\title{
UNIVERSITY STUDY OF AVIATION SPECIALISTS AT THE FACULTY OF AERONAUTICS OF THE TECHNICAL UNIVERSITY OF KOŠICE
}

\section{F. Adamčík}

Faculty of Aeronautics of the Technical University of Košice, Department of Avionics, Rampová 7, 04121 Košice, Slovak Republic. E-mail: Frantisek.Adamcik@tuke.sk Received 16 July 2007, accepted 10 Oct 2007

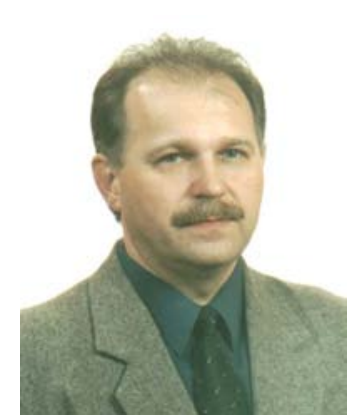

František ADAMČÍK, Assoc Prof, $\mathrm{PhD}$, Eng Date and place of birth: 1956 in Košice, Slovak Republic.

Education: Technical University of Košice, Faculty of Electrical Engineering (1980). Affiliations and functions: Air Force Academy in Košice, senior lecturer at the Air Force Academy (1981-2000); 1995 - PhD degree from the Department of Avionics and Weapon Systems of the Air Force Academy in Košice; 1999 - associate professorship in the scientific branch aircraft technical equipment; vice-rector responsible for education at Air Force Academy in Košice (2000-2004); since 2005 - vice-dean for education of Faculty of Aeronautics at the Technical University of Košice.

Research interests: aircraft electrical power systems, computer simulation in the education of avionics systems.

Experience: Co-organizer of conferences New Development Trends in Aeronautics.

Publications: Over 40 scientific articles.

Present position: Associate professor in the Department of Avionics (Aeronautics Faculty at the Technical University of Košice), Tel./Fax: +421556335192.

\begin{abstract}
The operation of air traffic generally covers a variety of activities, which, in some cases, have to be carried out by highly trained specialists. Their professional preparation, the scale and depth of the knowledge and skills of the personnel working on aircraft and in airports and in related areas of activities, must meet the requirements defined in aviation legislation. Quality education focusing on security factors and designed for air traffic personnel is absolutely necessary for the proper fulfilment of the tasks connected with air traffic jobs.
\end{abstract}

Keywords: education of aviation personnel, educational programs, aviation legislation.

\section{Introduction}

A university and a lifelong study of pilots and air technical personnel was in the past provided by the Gen. M.R. Stefanik Air Force Academy that was established in Kosice in the former Czechoslovakia in 1972 and continued its work in Slovakia for more than 30 years, even after the republics split.

Beginning in 1991 the accredited university was an integral part of the republic's school system and focused on the preparation of military and civilian students. Its graduates had been trained as aircraft pilots and specialists in air traffic control, aerial management, aerial engineering, and aerial electrical engineering.

A transformational process that military universities underwent led to the Air Force Academy being incorporated with the Technical University of Kosice on 1 September 2004, and it commenced its existence on 1 May 2005 as the ninth faculty of the Technical University of Kosice with the name of Faculty of Aeronautics as a successor of the former Air Force Academy - a university acknowledged both in Europe and in the world. It became a follower of long-term experience in training of both civilian and military pilots and air specialists.

\section{Faculty of Aeronautics}

The basic mission of the Faculty of Aeronautics is to contribute to the mission of the Technical University in air technologies, aviation, aeronautics, and related spheres. The Faculty of Aeronautics provides and organises education in study specialities in all three levels of university degrees. Study is focused on science and technology in compliance with the current status quo. A necessary part of the training of air personnel is also lifelong learning in the form of specialised courses and retraining courses of study in air control and operational technologies with a strongly practical or theoretical character for achieving the skills and habits necessary to perform particular activities.

The Faculty of Aeronautics provides university education in all three levels of degrees in accredited study programs that follow the requirements of national and European legislation and European Aviation Law (Fig). It is a holder of the Slovak Republic Civil Aviation Authority certificate of specialised competence to provide theoretical preparation in pilot training (JAR-FCL1) and the certificate for PART147 Maintenance Training Organization Approval, which authorises the faculty to 
train air technical personnel according to the requirements of European Union Aviation Legislation, which also considerably widens the ability of graduates to find employment abroad [2].

The organisation of all degrees and forms of university study is based on a credit system according to the principals of the European Credit Transformation System (ECTS), which enables the evaluation of a student's load depending on graduated study program units in accordance with the regulations included in a particular study programme. A student's academic year standardised load is expressed in the total number of 60 credits.

The transformation into a three degree model of university education has created conditions for the full use of all available advantages: study compatibility in the Slovak Republic and European Union, mobility of students (a credit-based system study), higher proficiency, motivation for their individual and independent work, of course, adapted in teaching methodology [3].
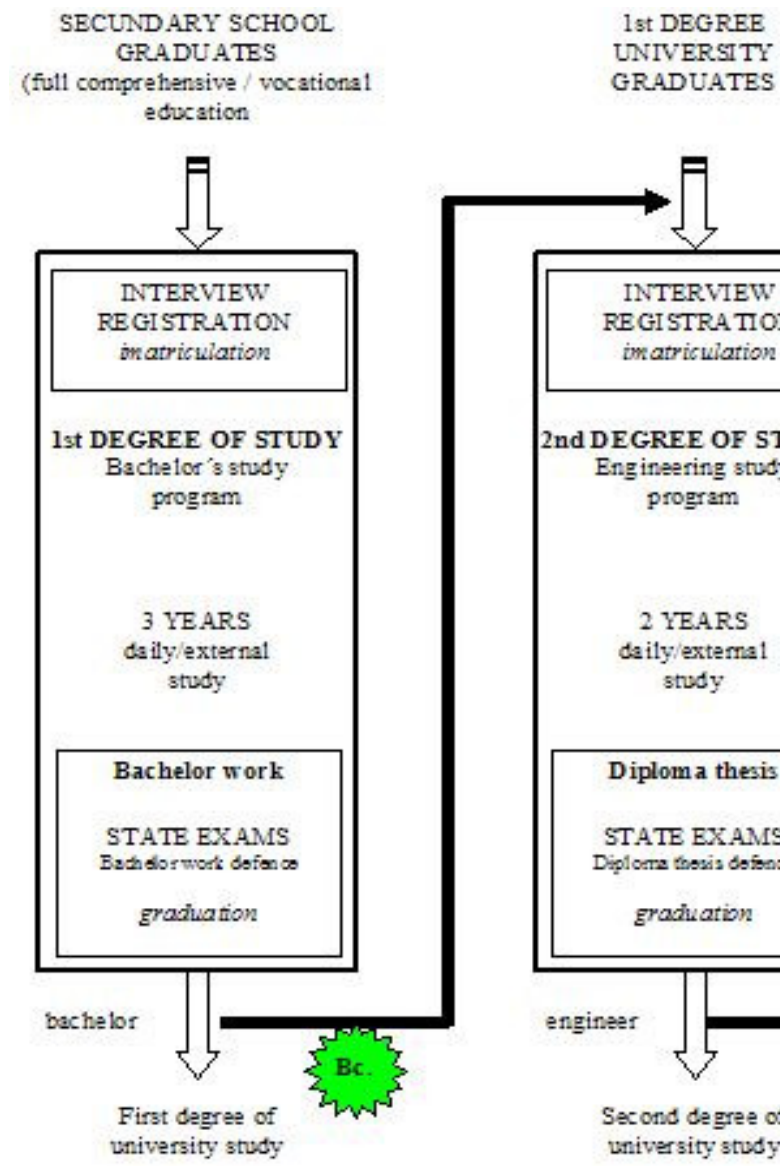

GRADUATES

UNIVERSITY

GRADUATES
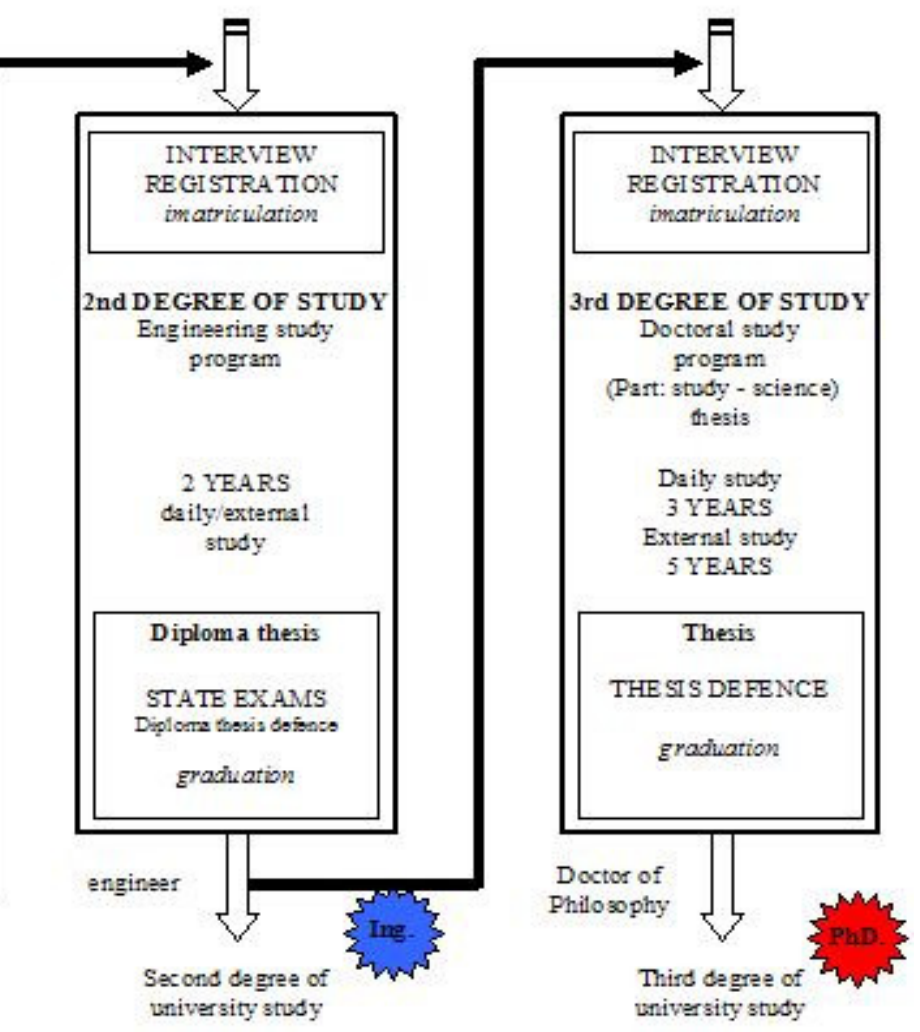

\section{WORK EXPERIENCE}

Fig. Three degrees of university studies

\section{Accredited study programmes}

The Faculty of Aeronautics has the following three degrees of accredited study programmes:

\section{Bachelor's degree}

- Professional pilot

- $\quad$ Air traffic controller

- Airport operation

- Aircraft operation

- Avionics systems

- Aviation and industrial magnetometers and sensors

- Electronic communication in aviation

- Military management
- Military pilot

- Aviation technical and operational support

Master's degree

- $\quad$ Air traffic management

- Aircraft operation

- Avionics systems

- Air security and industrial sensors

- Electronic communication in aviation

Doctoral degree

- Aircraft operation

- $\quad$ Air and industrial electronic systems 


\section{Capacity of study programmes}

\section{Professional pilot study programme}

This programme has the goal of providing the knowledge and skills necessary for aviation transport operators to work as professional pilots, and to do other aviation related jobs. The programme aims to provide the required theoretical preparation for a student to be able to perform, at the same time, practical training at a selected aviation school up to the level necessary for practical competence that would enable the student to acquire the qualification of business pilot.

After finishing flight training, a student can pass a theoretical and practical exam conducted by the Civil Aviation Authority of the Slovak Republic in a suitable type of airplane.

\section{Air traffic controller study programme}

The goal of the programme is to provide students the knowledge and skills necessary to perform the activities of air traffic controlling for air traffic operators as well as to hold posts to meet the appropriate requirements for air traffic controls in compliance with European aviation regulations. Another aim of the study program is to provide a student with a complete bachelor's education in the profession and at the same time enable the student to pass the theoretical exams that together with the health tests and health background check allow the student to acquire a "student air traffic controller" licence. The theoretical preparation is organised so that during studies a student has the option of obtaining basic practical skills on ATC simulators.

\section{Study programmes in the sphere of management}

These programmes have the goal of providing students the knowledge that they need to solve the routine technological and economic problems of aviation traffic. Students acquire knowledge about aviation technology and the principals of leading work groups and learn about relevant legislation and legal standards, economics, and the use of information technologies. Students also learn the basic methods of planning, organising and managing aviation traffic. Graduates of these programs can be employed as airport or aviation company workers. Since these study programs were created so that they provide a wide range of knowledge in the spheres of management, economics, law, and informatics, they guarantee the successful activities of the graduates in other branches as well. After finishing studies, graduates can decide to work or continue in the following engineering study programme.

The graduates of the engineering study programme are highly skilled, qualified, university-educated specialists who can organise, manage and control aviation operations, airports, and aviation equipment operations. They are prepared for air traffic planning and the economic and business activities of organs and organisations operating, controlling and overseeing air traffic and specific aviation work at home and abroad. They have knowledge of modern traffic technologies, and they master control methods and modern information technologies needed for traffic system control. They are able to solve complex problems of aviation traffic individually and creatively and to use modern means of decision support and optimise the operation of aviation traffic systems and their parts.

\section{Study programmes in the sphere of aviation engineering}

The bachelor's degree study programme Airplane Operation has the aim of imparting basic knowledge in general mechanical engineering, air mechanical engineering, diagnostics and air technical skills and fault detection, control and diagnostic equipment servicing, airplane maintenance and repair, air technical and operational support, preparation and training of the personnel as required by international aviation regulations. Graduates of this study programme are prepared to perform the functions of airplane operation technical workers according to European aviation regulations.

The Airplane Operation engineering study program has the goal of completing the knowledge imparted in the bachelor's degree program and its extension to the engineering level. The graduates of this study program are able to analyse, propose, construct, operate and maintain the means of transport within a given specialisation. They are able to use solutions with high creativity, complexity, independence and responsibility. They obtain knowledge in the area of theoretical engineering and in the areas of constructing, projecting, and operating means of air transport within a given specialisation. They are able to formulate the required scientific approach and professional perspective for applications in which they will use advanced methods and techniques of design, development and operation of air means of transport and their systems by obtaining experience in formulating and verifying hypotheses and experimental proposals and analysing the data obtained.

The aim of the Aircraft Operation doctoral study programme is to provide students the tools to master scientific methods and the development of air means of transport. Graduates are able to solve the most demanding scientific and research tasks focused on developing diagnostic systems and means of air transport as well as their testing and certification.

Graduates learn the principles of management, scientific work done independently or as a member of a team, scientific research, and the formulation and solution of complex scientific problems and presentation of scientific results. Graduates are also able to analyse and solve complex and non-standard tasks in a specialisation and to come with their own original and new solutions.

Students who complete this program can find jobs in research, development and design agencies solving problems and proposals and analyses in terms of high technology applications in, private and government sector, or work as a member of teaching faculty or research team sector at universities.

Study programmes in the sphere of aviation electronics

The Avionics Systems bachelor's degree study program has the goal of providing knowledge about 
electronics and cybernetics; electrical, special, radio, radio technical equipment and operational airplane security; aviation technology diagnostics and fault detection; control measuring services and diagnostic equipment; maintenance and repairs of on-board airplane systems; and the information and adequate practical experience defined by European aviation regulations. The graduates of this study programme are able to solve practical problems of electronic system operations in the sphere of their aviation applications and cooperate with managers and aviation company specialists or repair and construction enterprises. They are also prepared to perform the functions of airplane operation technicians according to European aviation regulations.

The Avionic Systems engineering study programme has the goal of supplementing the knowledge achieved in the bachelor's degree study programme and extending this knowledge to the engineering level. The graduates of this study programme are able to specify, propose, introduce and maintain vast integrated solutions, with a focus on electronic systems on board airplanes, and to work on projects that include identification of a problem and the analysis, proposal and implementation of solutions together with testing and adequate documentation of particular quality aspects. They are able to work effectively as independent workers or team members or lead work groups. They can also manage big projects in the sphere of electronic systems on board airplanes. They are able to take responsibility for complex and progressive solutions in this particular area and to organise education and professional development. They manage to maintain contact with the latest developments in their specialty and to follow adequate procedures in compliance with professional, legal and ethical frameworks.

The Aviation and Industrial Electronic Systems doctoral study programme is focused on theoretical knowledge and practical experience from key electronic spheres at the level of the current state of research in the world in compliance with the aim of a thesis. Graduates learn the principals of independent and team research work, scientific research, the scientific formulation of problems, and the presentation of scientific results. Students who finish this programme are also able to analyse and solve complex and non-standard tasks in the branch of electronics. Graduates are able to introduce new solutions, monitor the latest scientific and research trends in electronics, and update their knowledge in the form of lifelong study. They manage to communicate and cooperate with scientific project managers and specialists of other professions, too. These graduates can find jobs in research, development, and design agencies solving complex problems, proposals and analyses in terms of high technologies applications in industry, private and government sectors or as a member of the teaching faculty or research team at universities.

\section{Conclusions}

1. The aim and content of study programs come out of current study programme content and qualification requirements included aviation regulations. The creation of the regulations was based on problem integration between the basic spheres-technical, economic and legalof air traffic operations. The aim of the module structure used for individual subjects was to create possibilities for grouping them into integrated parts or into higher study units. It will be possible to interchange, suppress, include, innovate and react according to actual practical requirements [1].

2. The approach introduced fully satisfies modern educational technologies with the use of electronic media and also respects the possibilities of further continuous study in the second (engineering) and third (doctoral) levels of university study or in the further education of aviation personnel in the form of specialised aviation and technical courses to obtain skills and habits in performing certain activities.

\section{References}

1. ADAMČÍK, F. Trends in education of the aviation technical personnel. In Proceedings of Conference Universities and the Bologna Declaration - A strategy of Changes, Brno 2000, p. 159, ISBN 80214-1560.

2. ED Decision No 2003/19/RM 28/11/2003. European Aviation Safety Agency.

3. Higher Education Law of the Slovak Republic. 2002, no. 131. 